\title{
IPM Synchronous Machine Drive Response to a Single-Phase Open Circuit Fault
}

\author{
Brian A. Welchko, Student Member, IEEE, Thomas M. Jahns, Fellow, IEEE, and Silva Hiti, Member, IEEE
}

\begin{abstract}
This paper investigates the steady-state and dynamic response of an interior permanent magnet (IPM) synchronous machine drive to a single-phase open-circuit fault. This fault results in rotational electromagnetic asymmetry on both the stator and rotor, making it difficult to analyze using classical $d q$-transformation techniques. This paper presents a new $d q$ synchronous-frame machine model that is capable of handling this highly asymmetrical fault condition, including the effects of $q$ axis magnetic saturation. Fault responses with two alternative post-fault control strategies are investigated

1) opening all of the inverter switches so that the machine behaves as an uncontrolled generator (UCG), with the two unfaulted phases connected to the inverter dc link via the antiparallel diodes;

2) shorting the two remaining unfaulted phases together using the inverter switches.

Results of this investigation show that the fault response is generally more benign using the UCG control strategy, with significantly lower phase currents and pulsating torque than corresponding values delivered using the phase-shorting strategy.
\end{abstract}

Index Terms-Inverter shutdown, IPM synchronous machine, open circuit fault, protection, variable speed drive.

\section{INTRODUCTION}

$\mathbf{I}$ NTERIOR permanent magnet (IPM) synchronous machines are attractive for a variety of applications because of their high power density, wide constant-power speed range, and excellent efficiency [1], [2]. However, faults in either the machine or inverter create special challenges in any type of PM synchronous machine drive because of the presence of spinning rotor magnets that cannot be turned off at will. It is very important to understand the IPM drive's fault response to any potential fault condition in order to prevent fault-induced damage to either the machine, the inverter, or to the connected load.

This paper investigates an important fault class for an IPM machine in which one of the phases becomes open-circuited. This type of fault can be caused by mechanical failure of a machine terminal connector, an internal winding rupture, or by an electrical failure in one of the inverter phase legs. The other

Manuscript received January 30, 2001; revised April 3, 2002. Recommended by Associate Editor J. Ojo. This work was supported in part by General Motors Advanced Technology Vehicles and the U.S. National Science Foundation under Award EEC-9731677. This paper was presented at the 16th Annual Applied Power Electronics Conference and Exposition (APEC), Anaheim, CA, March 4-8, 2001.

B. A. Welchko and T. M. Jahns are with the Department of Electrical and Computer Engineering, University of Wisconsin, Madison, WI 53706 USA (e-mail: bwelchko@ieee.org).

S. Hiti is with the the Advanced Technology Vehicles Department, General Motors, Torrance, CA 90505 USA.

Publisher Item Identifier 10.1109/TPEL.2002.802180. major fault class for IPM machines consists of short-circuit faults that have been addressed in a separate investigation [3].

Classic $d q$ analysis techniques work well when electromagnetic asymmetries are limited to only the stator or rotor. Techniques such as harmonic balance [4] have been developed to provide steady-state analyses of synchronous machines with unequal stator winding impedances and unbalanced (but defined) phase voltage excitation waveforms. However, unbalanced open-circuit faults in an IPM synchronous machine poses special problems for applying $d q$ analytical techniques because the open circuit condition leaves at least one of the machine terminal voltages undefined by the external source. Kerkman and Lipo [5] presented a $d q$ model for analyzing open-circuit faults in wound-field synchronous machines using the magnetic flux linkages as the state variables. Recent investigations of permanent magnet synchronous machine faults focused on simulation results for a variety of different faults in a particular IPM machine [6] and experimental measurements of fault responses in a surface magnet synchronous machine [7].

This paper presents a new $d q$ model for an IPM machine with a single-phase open circuit condition that uses currents rather than flux linkages for the state variables. This approach introduces a carefully chosen variable substitution to simplify the analytical model compared to the previously published flux linkage model [5], reducing the IPM machine dynamics to a single nonlinear differential equation. Magnetic saturation effects that are important in IPM machines are easily introduced into this new current-based model without the need for solving nonlinear equations that is typically required in flux linkage formulations [8].

In addition to presenting the new model, this paper investigates two alternative post-fault inverter control strategies. The first control strategy is to remove gate excitation from all of the inverter switches so that the two remaining phases are connected to the dc bus only by the antiparallel diodes acting as uncontrolled rectifiers. This strategy will be referred to as uncontrolled generation (UCG) operation because the machine delivers energy back to the dc link through the rectifiers without any active inverter control. A previous investigation of this phenomenon [9] was limited to balanced three-phase conditions.

The second strategy is to short the two unfaulted phases together by turning on either the upper or lower inverter switches in each of these phases, thereby connecting the two machine terminals to one of the inverter dc buses.

Analytical techniques appropriate for the single-phase IPM machine fault condition are presented in Section II, followed by presentations of simulation and experimental verification test results. 


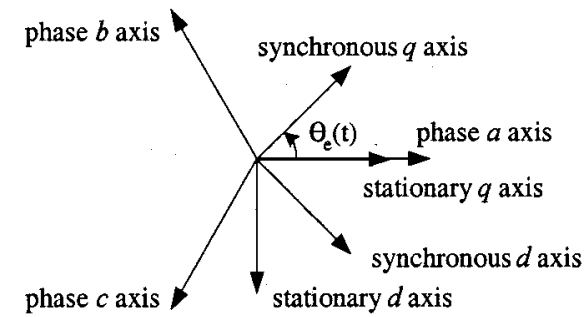

Fig. 1. Reference frame definitions.

\section{Motor Model Derivation}

The usual $d q$ model for an IPM machine [1], [2] assumes that the terminal voltages are always defined. This assumption is no longer valid when one phase opens, making it necessary to derive a new model. This model takes a special form since the fault condition appears in the stationary reference frame while the synchronous machine calls for adoption of a synchronouslyrotating reference frame to handle the rotor's electromagnetic asymmetry.

For the purpose of developing a $d q$ model of the IPM machine with one of the phases open-circuited, it will be assumed that phase $a$ is open-circuited and phases $b$ and $c$ continue to be connected to a driving voltage source specified by the system. It is relatively simple to adapt the resulting model such that one of the other phases is the one with the open circuit. Fig. 1 shows the reference frame definitions [10] used for this derivation.

Transformation equations to convert variables from the stationary $a b c$ reference frame to the stationary $d q$ reference frame and back again are given as

$$
\begin{aligned}
& {\left[\begin{array}{l}
f_{q}^{s} \\
f_{d}^{s}
\end{array}\right]=\frac{2}{3}\left[\begin{array}{ccc}
1 & -\frac{1}{2} & -\frac{1}{2} \\
0 & -\frac{\sqrt{3}}{2} & \frac{\sqrt{3}}{2}
\end{array}\right]\left[\begin{array}{l}
f_{a}^{s} \\
f_{b}^{s} \\
f_{c}^{s}
\end{array}\right]} \\
& {\left[\begin{array}{l}
f_{a}^{s} \\
f_{b}^{s} \\
f_{c}^{s}
\end{array}\right]=\left[\begin{array}{cc}
1 & 0 \\
-\frac{1}{2} & -\frac{\sqrt{3}}{2} \\
-\frac{1}{2} & \frac{\sqrt{3}}{2}
\end{array}\right]\left[\begin{array}{l}
f_{q}^{s} \\
f_{d}^{s}
\end{array}\right]}
\end{aligned}
$$

where $f$ is a dummy variable representing a machine voltage, current, or flux, and the superscript $s$ designates a variable in the stationary reference frame.

The transformations between the synchronously-rotating and stationary frames are

$$
\begin{aligned}
& {\left[\begin{array}{l}
f_{q}^{e} \\
f_{d}^{e}
\end{array}\right]=\left[\begin{array}{cc}
\cos \theta_{e} & -\sin \theta_{e} \\
\sin \theta_{e} & \cos \theta_{e}
\end{array}\right]\left[\begin{array}{l}
f_{q}^{s} \\
f_{d}^{s}
\end{array}\right]} \\
& {\left[\begin{array}{l}
f_{q}^{s} \\
f_{d}^{s}
\end{array}\right]=\left[\begin{array}{cc}
\cos \theta_{e} & \sin \theta_{e} \\
-\sin \theta_{e} & \cos \theta_{e}
\end{array}\right]\left[\begin{array}{l}
f_{q}^{e} \\
f_{d}^{e}
\end{array}\right]}
\end{aligned}
$$

where the superscript $e$ designates variables in the synchronous reference frame (see Fig. 1).

Having chosen phase $a$ as the faulted phase so that $i_{a}=0$, and assuming that the machine is wye-connected with a floating neutral so that $i_{0}^{s}=i_{0}^{e}=0,(2)$ and (4) lead to

$$
i_{q}^{s}=0=i_{q}^{e} \cos \theta_{e}+i_{d}^{e} \sin \theta_{e}
$$

where $\theta_{e}$ is the angle defining the orientation of the synchronous reference frame as shown in Fig. 1.

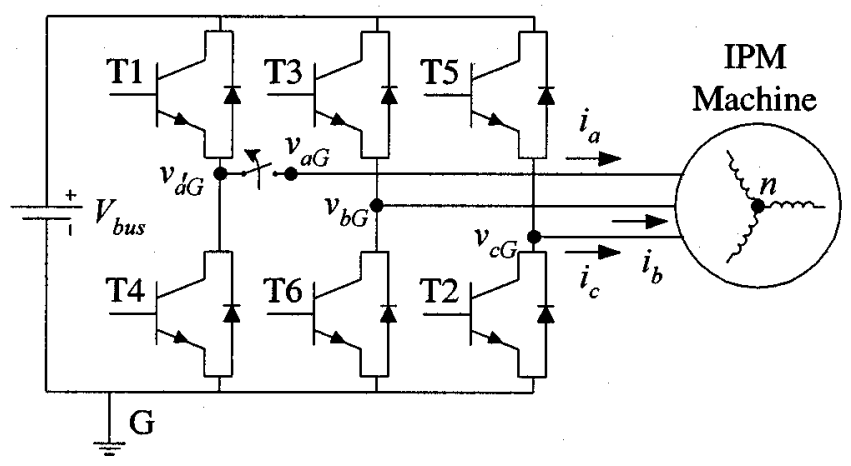

Fig. 2. IPM machine drive with an open-circuit in phase $a$, showing terminal definitions. The machine is wye-connected with a floating neutral $n$.

The inverter output voltages can be defined relative to the negative bus terminal (designated by a subscript $G$ ) as shown in Fig. 2, and expressed as

$$
v_{a G}^{s}=v_{a n}^{s}+v_{n G}^{s}, \quad v_{b G}^{s}=v_{b n}^{s}+v_{n G}^{s}, \quad v_{c G}^{s}=v_{c n}^{s}+v_{n G}^{s}
$$

where $v_{n G}^{s}$ is the voltage between the floating machine neutral and the negative bus.

From (1) and (6), the $d$ - and $q$-axis voltages in the stationary frame can be rewritten in terms of the inverter output voltages as follows:

$$
\begin{aligned}
v_{d}^{s} & =\frac{1}{\sqrt{3}}\left[-v_{b n}^{s}+v_{c n}^{s}\right]=\frac{1}{\sqrt{3}}\left[v_{c G}-v_{b G}\right] \\
v_{q}^{s} & =\frac{2}{3}\left[v_{a n}^{s}-\frac{1}{2} v_{b n}^{s}-\frac{1}{2} v_{c n}^{s}\right] \\
& =\frac{2}{3}\left[v_{a G}-\frac{1}{2} v_{b G}-\frac{1}{2} v_{c G}\right] .
\end{aligned}
$$

The stationary $d$ axis voltage $v_{d}^{s}$ given in (7) is a known quantity at all times since both phases $b$ and $c$ remain connected to the inverter. In contrast, $v_{q}^{s}$ given by (8) is not determined by the inverter since the phase $a$ machine terminal is open-circuited, creating a floating terminal voltage $v_{a G}$. Knowledge of $v_{d}^{s}$ and $i_{q}^{s}(=0)$ provide necessary and sufficient stator terminal constraints to derive a full solution for this open-circuit operating mode.

The $d q$ equations for an IPM machine in the synchronous frame [2], [8] are given by

$$
\begin{aligned}
v_{q}^{e} & =r_{s} i_{q}^{e}+p \lambda_{q}+\omega_{e} \lambda_{d} \\
v_{d}^{e} & =r_{s} i_{d}^{e}+p \lambda_{d}-\omega_{e} \lambda_{q} \\
\lambda_{q} & =L_{q s} i_{q}^{e} \\
\lambda_{d} & =L_{d} i_{d}^{e}+\Psi_{\operatorname{mag}}
\end{aligned}
$$

where $r_{s}, L_{d}, L_{q}$, and $\Psi_{\operatorname{mag}}$ are the stator resistance, $d$ axis and $q$ axis inductances, and the permanent magnet flux linkage, respectively. Previous researchers have recognized that magnetic saturation has a significant impact on the operating characteristics of IPM machines [1], [2], [11], [12]. In particular, the $q$ axis inductance is highly susceptible to saturation and can be modeled quite accurately by making $L_{q}$ a function of the $q$ axis current, $i_{q}^{e}$, while treating $L_{d}$ as a constant. Cross-coupling saturation effects between the two axes are assumed to be small and 
are not included in this model. Equation (9) can be rewritten using (11) plus chain differentiation to reflect the fact that $L_{q}$ is a function of $i_{q}^{2}$

$$
v_{q}^{e}=r_{s} i_{q}^{e}+L_{q} \frac{d i_{q}^{e}}{d t}+i_{q}^{e}\left(\frac{d L_{q}}{d i_{q}^{e}} \frac{d i_{q}^{e}}{d t}\right)+\omega_{e} L_{d} i_{d}^{e}+\omega_{e} \Psi_{\mathrm{mag}} .
$$

By defining a saturating inductance term

$$
L_{q}^{\prime}=L_{q}+i_{q}^{e}\left[\frac{\partial L_{q}}{\partial i_{q}^{e}}\right]
$$

(13) can be simplified. The resulting $q$ axis voltage equation is expressed as follows, together with its companion $d$-axis equation, both expressed in terms of the axis currents rather than the flux linkage variables found in (9) and (10)

$$
\begin{aligned}
& v_{q}^{e}=r_{s} i_{q}^{e}+L_{q}^{\prime} \frac{d i_{q}^{e}}{d t}+\omega_{e} L_{d} i_{d}^{e}+\omega_{e} \Psi_{\mathrm{mag}} \\
& v_{d}^{e}=r_{s} i_{d}^{e}+L_{d} \frac{d i_{d}^{e}}{d t}-\omega_{e} L_{q} i_{q}^{e} .
\end{aligned}
$$

Torque production in the IPM machine is given by

$$
T_{e m}=1.5 P\left[i_{q} \Psi_{\operatorname{mag}}+\left(L_{d}-L_{q}\right) i_{q} i_{d}\right]
$$

where $P$ is the number of pole-pairs.

Using the transformation (4), the stationary-frame $d$ axis voltage can be expressed as

$$
v_{d}^{s}=-v_{q}^{e} \sin \theta_{e}+v_{d}^{e} \cos \theta_{e} .
$$

Equations (15) and (16) can be substituted into (18) to give

$$
\begin{aligned}
v_{d}^{s}= & -r_{s} i_{q}^{e} \sin \theta_{e}-L_{q}^{\prime} \frac{d i_{q}^{e}}{d t} \sin \theta_{e}-\omega_{e} \Psi_{\operatorname{mag}} \sin \theta_{e} \\
& -\omega_{e} L_{d} i_{d}^{e} \sin \theta_{e}+r_{s} i_{d}^{e} \cos \theta_{e} \\
& +L_{d} \frac{d i_{d}^{e}}{d t} \cos \theta_{e}-\omega_{e} L_{q} i_{q}^{e} \cos \theta_{e} .
\end{aligned}
$$

Although it is tempting to use the $i_{a}=0$ current constraint expressed in (5) to eliminate one of the two axis current variables in (19), the resulting differential equations suffer from periodic singularities since the expressions $\sin \theta_{e}$ or $\cos \theta_{e}$ appear as denominator terms. In order to eliminate these singularities, it is useful to define two new auxiliary variables for use in the resulting differential equations. These new variables are defined as

$$
\rho=\frac{i_{q}^{e}}{\sin \theta_{e}}, \quad \xi=\frac{i_{d}^{e}}{\cos \theta_{e}} .
$$

Substituting (20) into (5) and solving leads to

$$
\xi=-\rho, \quad \frac{d \xi}{d t}=-\frac{d \rho}{d t} .
$$

Differentiating the newly defined auxiliary variables in (20) yields

$$
\begin{aligned}
& \frac{d \rho}{d t}=\frac{1}{\sin \theta_{e}} \frac{d i_{q}^{e}}{d t}-\frac{\omega_{e} \cos \theta_{e}}{\sin \theta_{e}} \rho \\
& \frac{d \xi}{d t}=\frac{1}{\cos \theta_{e}} \frac{d i_{d}^{e}}{d t}+\frac{\omega_{e} \sin \theta_{e}}{\cos \theta_{e}} \xi .
\end{aligned}
$$

Equations (22) and (23) can be solved for the current derivatives as

$$
\begin{aligned}
\frac{d i_{q}^{e}}{d t} & =\frac{d \rho}{d t} \sin \theta_{e}+\omega_{e} \rho \cos \theta_{e} \\
\frac{d i_{d}^{e}}{d t} & =\frac{d \xi}{d t} \cos \theta_{e}-\omega_{e} \xi \sin \theta_{e} .
\end{aligned}
$$

Substituting (20), (24) and (25) into (19) makes it possible to express the $d$ axis voltage in terms of the new auxiliary variables $\rho$ and $\xi$

$$
\begin{aligned}
v_{d}^{s}= & -r_{s} \rho \sin ^{2} \theta_{e}-L_{q}^{\prime} \sin \theta_{e}\left[\omega_{e} \rho \cos \theta_{e}+\frac{d \rho}{d t} \sin \theta_{e}\right] \\
& -\omega_{e} \Psi_{\operatorname{mag}} \sin \theta_{e}-\omega_{e} L_{d} \xi \cos \theta_{e} \sin \theta_{e}+r_{s} \xi \cos ^{2} \theta_{e} \\
& +L_{d} \cos \theta_{e}\left[-\omega_{e} \xi \sin \theta_{e}+\frac{d \xi}{d t} \cos \theta_{e}\right] \\
& -\omega_{e} L_{q} \rho \sin \theta_{e} \cos \theta_{e}
\end{aligned}
$$

Equation (26) can be rearranged and simplified in terms of $\rho$ only by using (21) and (22) to give

$$
\begin{aligned}
\frac{d \rho}{d t}= & {\left[-r_{s} \rho+\omega_{e} \rho\left[L_{d}-\frac{L_{q}^{\prime}+L_{q}}{2}\right] \sin \left(2 \theta_{e}\right)\right.} \\
& \left.-\omega_{e} \Psi_{\operatorname{mag}} \sin \theta_{e}-v_{d}^{s}\right] \\
& \cdot\left[\frac{1}{L_{q}^{\prime} \sin ^{2} \theta_{e}+L_{d} \cos ^{2} \theta_{e}}\right] .
\end{aligned}
$$

Equation (27) completely characterizes the electrical response of the IPM synchronous machine when phase $a$ is opencircuited. Notice that this system is reduced in order from two to one compared with the usual case of three-phase excitation. During normal operation, two of the three phase currents are independent in a three-wire, wye-connected system. As soon as one of the phases becomes disconnected, only one of the two remaining phase currents can be independent since the two currents must still add to zero to satisfy Kirchoff's law. As a result, only one differential equation is required to characterize the single independent current when one phase is open-circuited.

Although (27) is expressed in terms of the auxiliary variable $\rho$, the simulation results can be conveniently converted back into the $d$ axis and $q$ axis currents using (20) and (21). Once this conversion is made, all of the desired phase variables and torque can be readily calculated using (1) to (17).

\section{SimUlation Results}

Using the model developed in Section II, two post-fault operating conditions were investigated via simulation using SIMULINK, with data post-processing in MATLAB. As described in Section I, the first control strategy is to remove gate excitation from all of the inverter switches so that the machine operates in its uncontrolled generation (UCG) mode [9] with the two active phases. The second strategy is to short the two unfaulted phases together by turning on either the upper or lower inverter switches in each of these phases. In both cases, phase $a$ remains open-circuited following initiation of the fault. It is worth noting that the UCG post-fault control strategy causes electrical energy to be delivered back to the dc link. Therefore, the UCG strategy is a practical option only for 
drive systems that are designed to safely accept this regenerated energy.

Parameters for a $70 \mathrm{~kW}$ (peak) IPM machine (see Appendix for values) were used for all of the simulation results shown in this section. The machine used in this paper was designed for propulsion in an electric vehicle with a battery pack voltage between 290 and $350 \mathrm{~V}$. The base speed is $4800 \mathrm{rpm}$ and the maximum rated operational speed is $7200 \mathrm{rpm}$. As a result, this particular IPM machine was not designed to achieve a wide range of constant-power operation. Instead, other performance objectives for which the IPM machine is well suited, including high torque density and high efficiency, dominated the design considerations.

The simulations were run with balanced three-phase excitation and a $50-\mathrm{kW}$ load prior to initiation of the open-circuit fault. In all of these simulations, it has been assumed that the open circuit is initiated in phase $a$ at a time instant when the phase $a$ current is naturally passing through zero. This approach avoids large inductive voltage transients at the machine terminals that complicate the analysis without having any other impact on the machine's dynamic fault response. The rotor speed and bus voltage for each simulation is individually specified.

\section{A. Two-Phase Uncontrolled Generator Response}

Figs. 3 and 4 show the simulated machine response when the control action of the inverter is to remove the gating pulses of phases $b$ and $c$ as soon as phase $a$ is open-circuited. For these simulations, the fault occurs at time $t=0$. The simulations were carried out for two bus voltages, 350 and $290 \mathrm{~V}$, corresponding to the maximum and minimum voltages, respectively, of a battery pack power supply.

The speed used for the simulations was $7200 \mathrm{rpm}$. This is the maximum speed in the desired operating range and represents a worst-case condition since the voltage difference between the machine's back-emf voltage and the bus voltage is largest under these conditions. Since the back-emf voltage is proportional to rotor speed, the post-fault currents disappear entirely when the speed drops to the point that the phase-leg diodes never become forward biased following fault initiation.

For both of the bus voltage conditions investigated, the resultant phase $b$ and $c$ currents are discontinuous. As a result, the system transitions to a steady-state operating point within the first electrical cycle. For the case of maximum bus voltage $(350 \mathrm{~V})$, the peak phase current is only $5.4 \mathrm{~A}$, while it increases to $30.8 \mathrm{~A}$ for minimum bus voltage $(290 \mathrm{~V})$. Both of these are significantly less than the machine's rated peak phase current of $154 \mathrm{~A}$ at $50 \mathrm{~kW}$ output power and $350 \mathrm{~V}$ bus.

Fig. 4 shows the electrical torque developed during two-phase UCG operation. The torque is pulsating in nature due to the discontinuous currents in the machine. The motor torque during UCG operation is always negative, corresponding to braking torque. This is consistent with the observation that the drive system can only regenerate energy to the dc link during this mode because of the diodes.

For the machine drive system studied, the braking torque amplitude is small with peaks of $-2.5 \mathrm{Nm}$ and $-11.7 \mathrm{Nm}$ for a $350-\mathrm{V}$ bus and $290-\mathrm{V}$ bus, respectively. Average braking torque

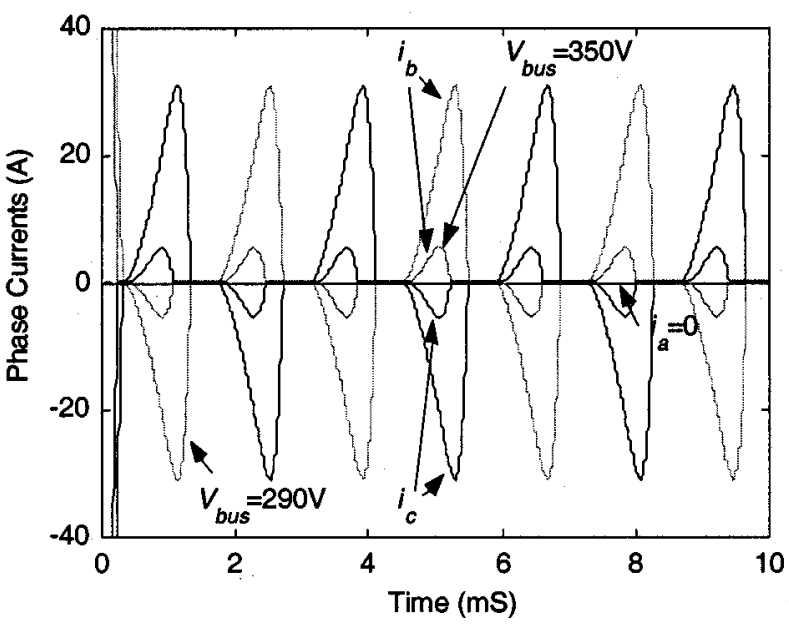

Fig. 3. Simulated phase currents for two-phase UCG post-fault operation at $\omega_{r}=7200 \mathrm{rpm}$ for max. and min. bus voltages. Fault is initiated at $t=0$.

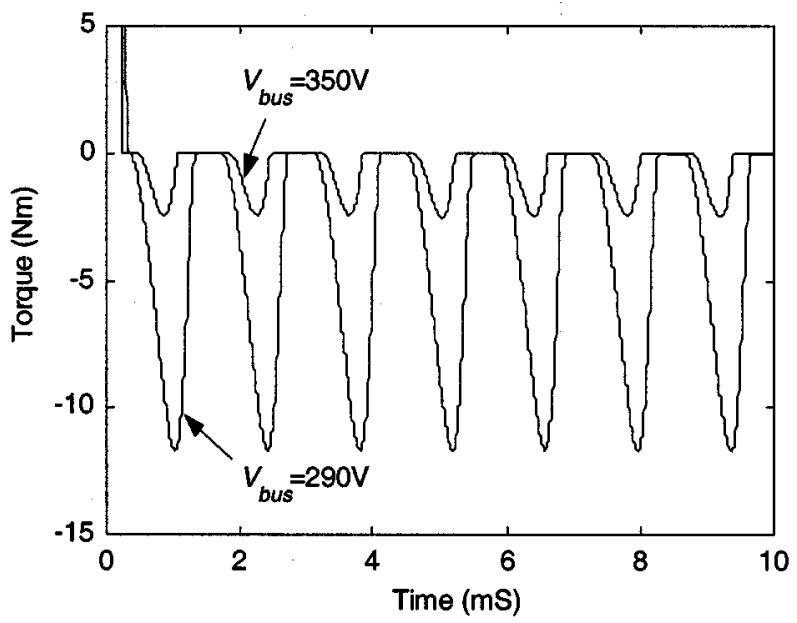

Fig. 4. Simulated motor torque for two-phase UCG post-fault operation at $\omega_{r}=7200 \mathrm{rpm}$ for max. and min. bus voltages.

TABLE I

COMPARISON OF AVERAGE MOTOR TORquefor Two-PHASE OPERATION

\begin{tabular}{c|c|c}
\hline Case & $\begin{array}{c}\text { Measured Average } \\
\text { Torque }(\mathrm{Nm})\end{array}$ & $\begin{array}{c}\text { Simulated Average } \\
\text { Torque }(\mathrm{Nm})\end{array}$ \\
\hline UCG, $\omega_{r}=7200 \mathrm{rpm}, V_{b u s}=290 \mathrm{~V}$ & -4.0 & -2.99 \\
\hline UCG, $\omega_{r}=7200 \mathrm{rpm}, V_{b u s}=350 \mathrm{~V}$ & -0.6 & -0.45 \\
\hline Short, $\omega_{r}=7200 \mathrm{rpm}$ & -- & -0.39 \\
\hline
\end{tabular}

values are even lower: $-0.45 \mathrm{Nm}$ and $-2.99 \mathrm{Nm}$ for 350 and $290 \mathrm{~V}$, respectively (see Table I). This compares to the prefault torque of $+66.3 \mathrm{Nm}$ corresponding to $50 \mathrm{~kW}$ output power at $7200 \mathrm{rpm}$.

As discussed in [9], the braking torque during UCG operation will increase if the permanent magnet flux linkage $\Psi_{\operatorname{mag}}$ is increased, boosting the available back-emf at any speed, and hence, boosting the resulting stator current as well. Thus, care must be taken in extrapolating the quantitative results for this machine to any other machine without carrying out the necessary analysis using the new machine's parameters. 


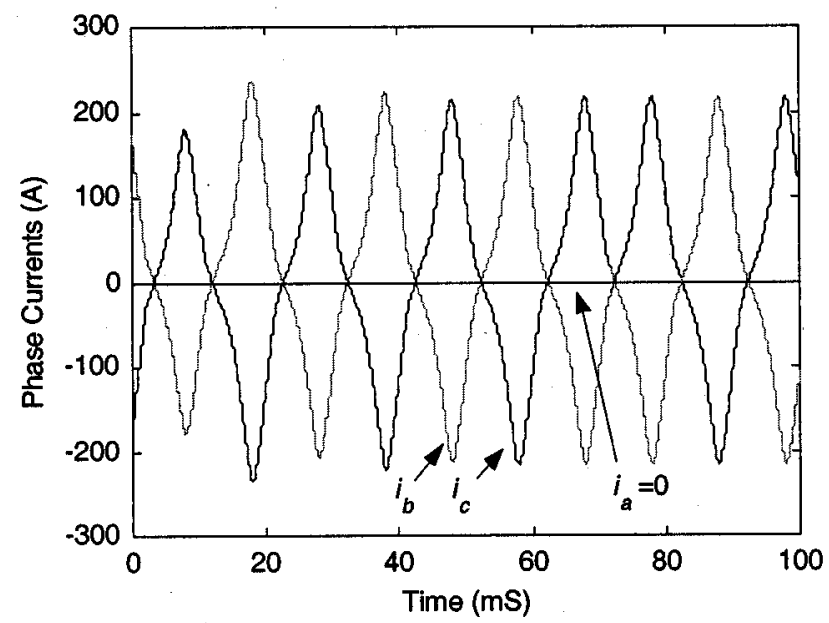

Fig. 5. Simulated two-phase short-circuit current waveforms at $\omega_{r}=$ $1000 \mathrm{rpm}$. Fault initiated at $t=0$.

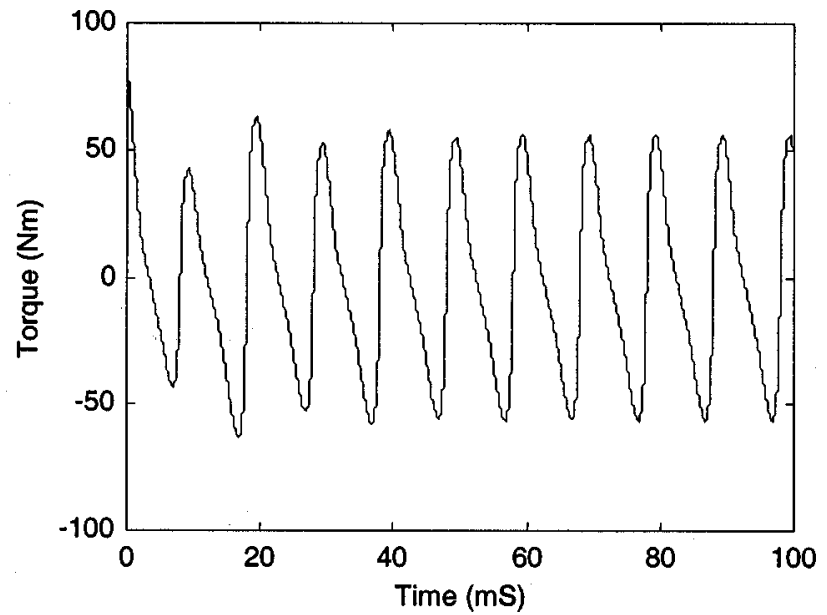

Fig. 6. Simulated two-phase short-circuit torque at $\omega_{r}=1000 \mathrm{rpm}$. Fault initiated at $t=0$.

\section{B. Two-Phase Short Circuit Response}

An alternative post-fault control strategy is to purposely short the two remaining machine phases (phases $b$ and $c$ ) by closing either the lower or upper pair of inverter switches for the conducting phases. This action has the effect of disconnecting the machine from the dc link power source.

Simulation results for this control strategy are presented in Figs. 5-8 for two rotor speeds, $1000 \mathrm{rpm}$ and $7200 \mathrm{rpm}$. For these simulations, a $d$ axis inductance of $0.35 \mathrm{mH}$ was used rather than the $0.4 \mathrm{mH}$ value appearing in Appendix. This lower value, reflecting modest saturation, corresponds to the measured $d$ axis inductance for the large values of $d$ axis current that are present under this post-fault condition.

These figures show that the machine response to the shorting of phases $b$ and $c$ is considerably different from the response with the UCG gate removal strategy. The amplitude of the stator current is quite high with the shorting strategy, reaching peak values exceeding 200 A that fall in the vicinity of peak currents experienced during $70-\mathrm{kW}$ peak power delivery. The average braking torque production is very low $(-0.39 \mathrm{Nm}$ as indicated in Table I), but the pulsating torque due to the un-

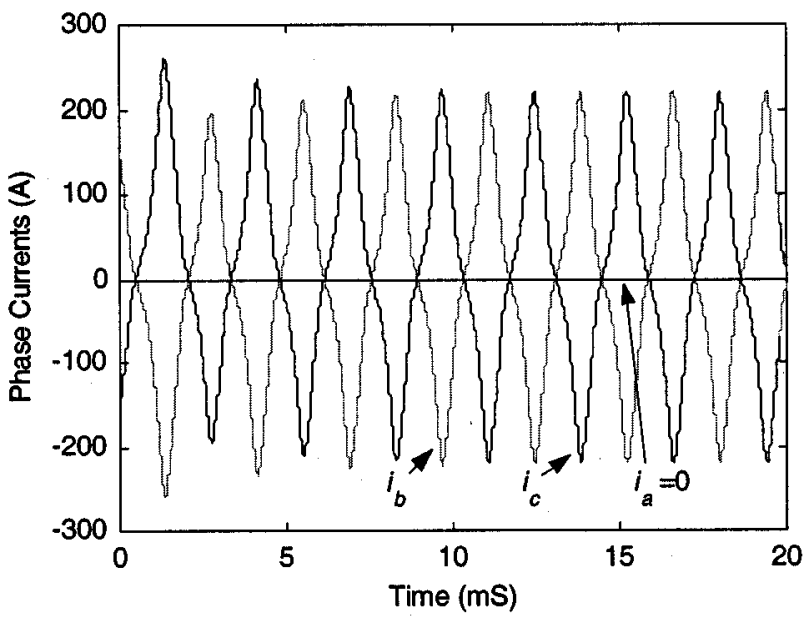

Fig. 7. Simulated two-phase short-circuit current waveforms at $\omega_{r}=$ $7200 \mathrm{rpm}$. Fault initiated at $t=0$.

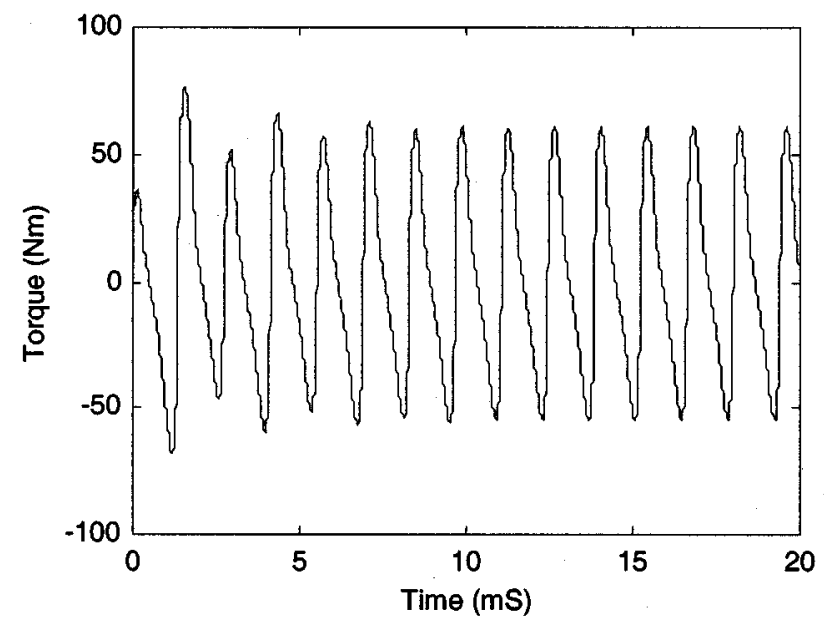

Fig. 8. Simulated two-phase short-circuit torque at $\omega_{r}=7200 \mathrm{rpm}$. Fault initiated at $t=0$.

balanced excitation is noticeably higher, reaching peak values of approximately $50 \mathrm{Nm}$. The shapes of the torque and current waveforms are not perfectly sinusoidal due to the effects of $q$ axis saturation.

Figs. 5-8 indicate that the peak values of the fault current and torque change little when the rotor speed is changed from $1000 \mathrm{rpm}$ to $7200 \mathrm{rpm}$. This is due to the fact that the back-emf and the machine reactances are all proportional to rotor speed (i.e., frequency), so that the resulting current associated with their ratio (i.e., E/X) is quite insensitive to speed. It is only at low speeds when the resistance effects become dominant that the currents and torque become increasingly speed-sensitive. This is seen in Fig. 9, which shows a ramp speed profile from 7200 to $0 \mathrm{rpm}$ during operation with phases $b$ and $c$ shorted. In this simulation, the current amplitudes remain nearly constant until the machine speed drops to values less than approximately $500 \mathrm{rpm}$, where the currents decay to 0 .

Since the drive system is incapable of transferring energy back to the dc link with the shorting strategy, the only places to dissipate braking energy in the machine are the stator resistances and iron core losses. Hence, the average value of braking 


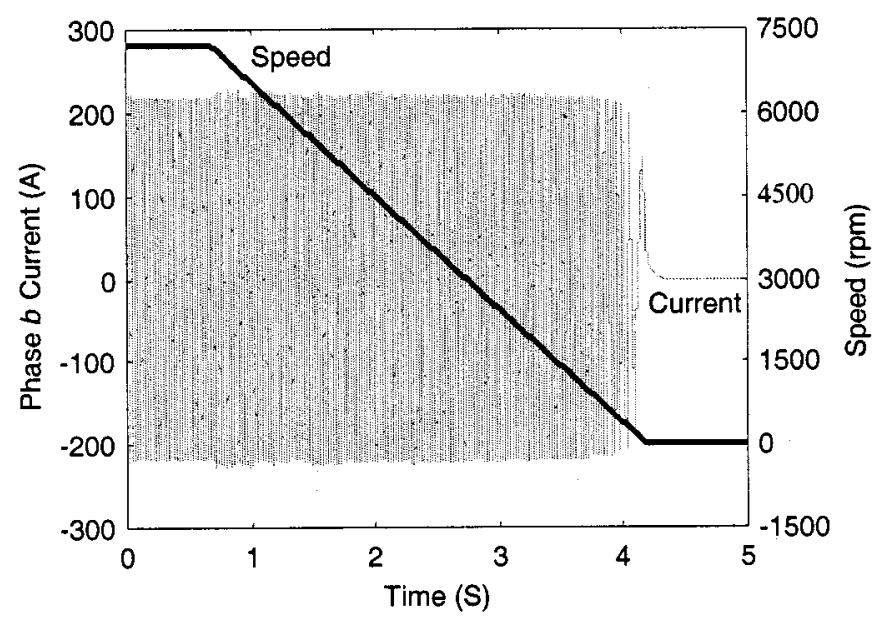

Fig. 9. Simulated speed ramp for two-phase short circuit from 7200 to $0 \mathrm{rpm}$.

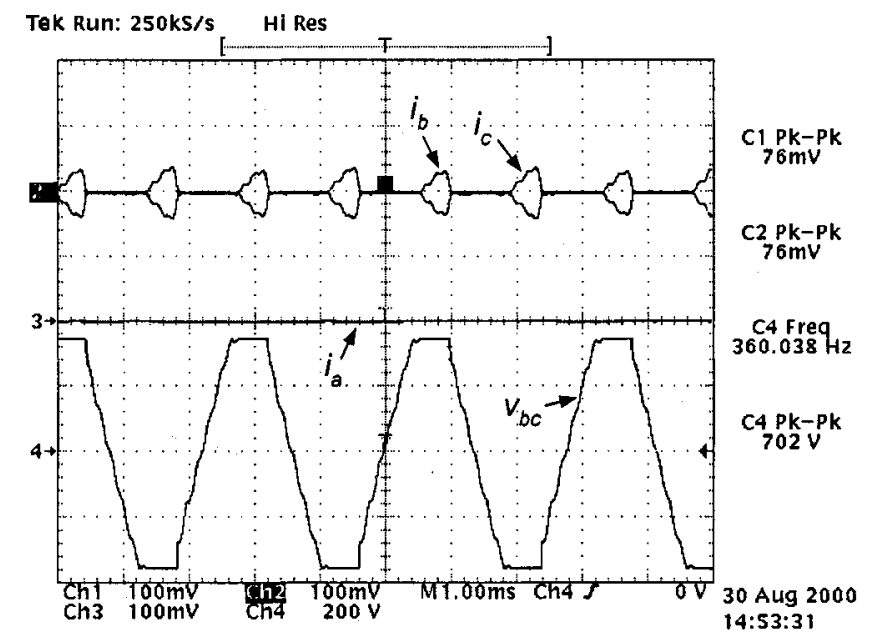

Fig. 10. Experimental two-phase UCG waveforms at $\omega_{r}=7200 \mathrm{rpm}$. $V_{\text {bus }}=350 \mathrm{~V} \cdot \operatorname{ch} 1=i_{b}, \operatorname{ch} 2=i_{c}, \operatorname{ch} 3=i_{a} .7 .5 \mathrm{~A} / \mathrm{div} . ; \operatorname{ch} 4=v_{b c}$, $200 \mathrm{~V} /$ div.

torque will be reduced if the machine design is modified to improve its efficiency.

\section{EXPERIMENTAL RESULTS}

Experimental verification tests were conducted to verify the developed IPM machine model for a single-phase open circuit fault and the resulting simulations. The tested IPM machine has the ratings and equivalent circuit parameter values provided in the Appendix.

Figs. 10 and 11 show the steady-state results of the machine response using the UCG control strategy. The line-to-line machine terminal voltage $v_{b c}$ is shown in addition to the phase $b$ and $c$ currents, highlighting the intervals when the phases are conducting. When the dc link voltage was set to $350 \mathrm{~V}$, the measured phase current had a peak value of 2.9 A compared with a simulated peak value of 5.4 A. For the same test with a $290-\mathrm{V}$ bus, the peak phase current was measured to be $28.2 \mathrm{~A}$, closely matching the simulated value of $30.8 \mathrm{~A}$. Waveshape agreement is also generally quite good.

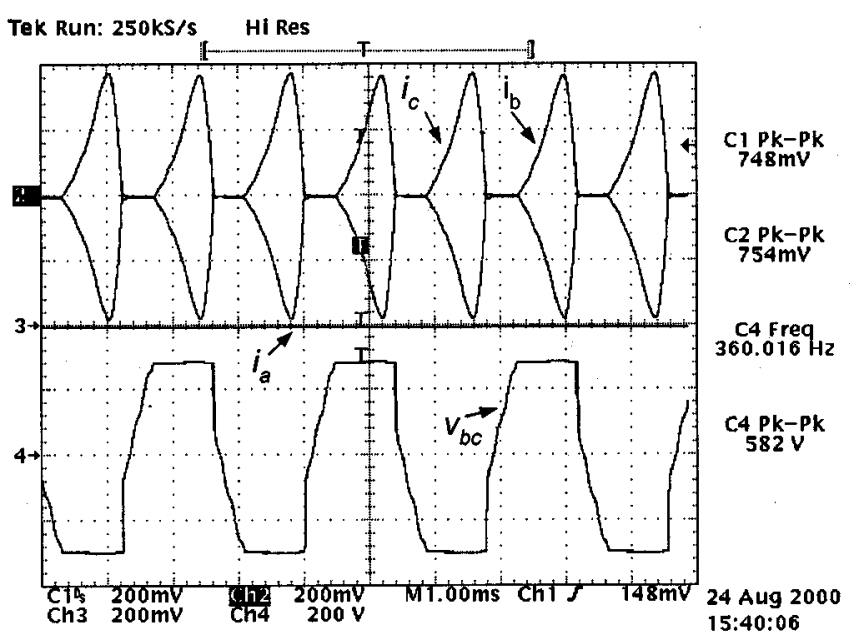

Fig. 11. Experimental waveforms with UCG strategy at $\omega_{r}=7200 \mathrm{rpm}$. $V_{\text {bus }}=290 \mathrm{~V} \cdot \operatorname{ch} 1=i_{b}, \operatorname{ch} 2=i_{c}, \operatorname{ch} 3=i_{a} .15 .0 \mathrm{~A} /$ div.; $\operatorname{ch} 4=v_{b c}$, $200 \mathrm{~V} /$ div.

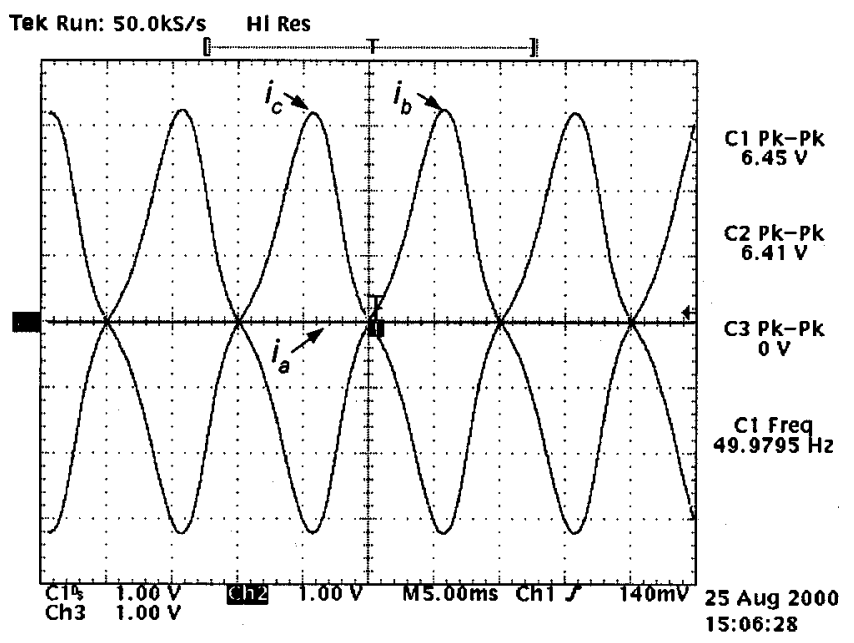

Fig. 12. Experimental two-phase short-circuit waveforms at $\omega_{r}=1000 \mathrm{rpm}$. $\operatorname{ch} 1=i_{b}, \operatorname{ch} 2=i_{c}, \operatorname{ch} 3=i_{a} ; 75.2 \mathrm{~A} /$ div.

The poorer quantitative agreement at the higher bus voltage is most likely caused by the fact that the machine is operating right on the edge of diode conduction under these conditions. This means that the low current amplitude depends on the difference between two nearly equal large numbers (i.e., the bus voltage and back-emf), causing a heightened sensitivity to errors in the measured machine parameters such as $\Psi_{\text {mag. }}$. In addition, parasitic loss parameters such as cable resistances and friction and windage losses are not included in the simulations, contributing additional error sources that can be significant under these operating conditions at the threshold of diode conduction.

Figs. 12 and 13 show measured steady-state phase currents when phases $b$ and $c$ are shorted while phase $a$ is open-circuited. Peak phase currents of 241 and 230 A were measured for speeds of 1000 and $7200 \mathrm{rpm}$, respectively. This compares to simulated peak values of 217 and $220 \mathrm{~A}$, respectively. These values are within $10 \%$ of the measured results, and the residual errors are 


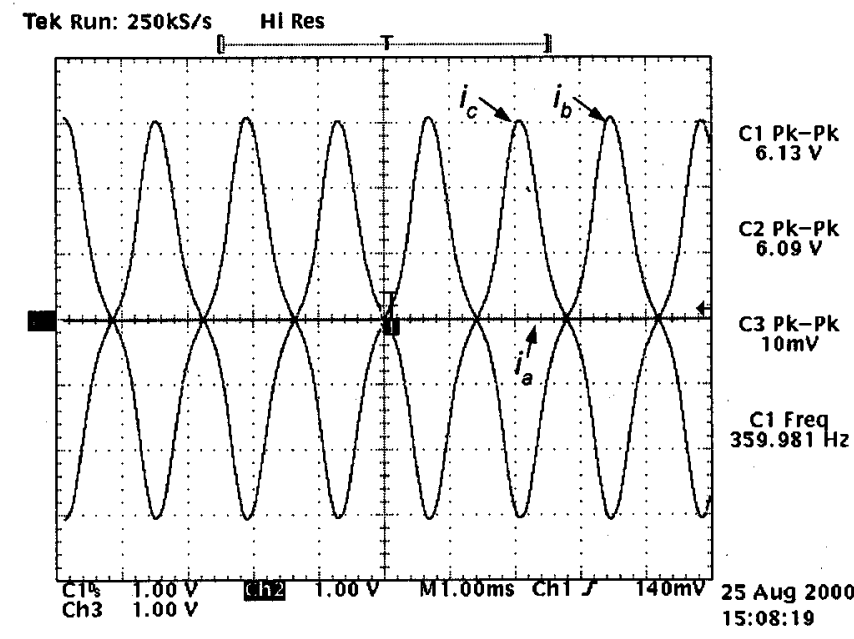

Fig. 13. Experimental two-phase short-circuit waveforms at $\omega_{r}=7200 \mathrm{rpm}$. $\operatorname{ch} 1=i_{b}, \operatorname{ch} 2=i_{c}, \operatorname{ch} 3=i_{a} ; 75.2 \mathrm{~A} / \mathrm{div}$

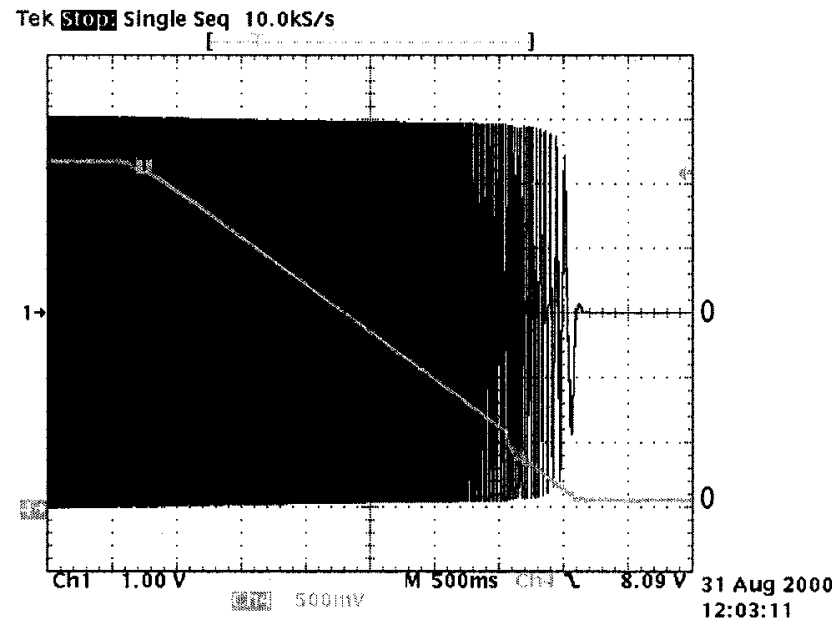

Fig. 14. Experimental two-phase short-circuit speed ramp from $7200 \mathrm{rpm}$ to $0 \mathrm{rpm} . \operatorname{ch} 1=i_{b}, 75.2 \mathrm{~A} / \mathrm{div} ; \operatorname{ch} 4=\omega_{r}, 1335 \mathrm{rpm} / \mathrm{div}$.

most likely caused by inaccurate measurements of the $d$ axis inductance for high values of $d$ axis current where saturation effects become more significant.

Fig. 14 shows one of the measured phase currents when the drive system was subjected to an externally applied speed profile from 7200 to $0 \mathrm{rpm}$ with one of the phases open-circuited and the remaining two phases shorted together. The measured stator current envelope matches the predicted envelope from Fig. 9 very well, verifying that the stator current is quite independent of speed until the speed drops below $500 \mathrm{rpm}$.

The average machine torque was measured for the UCG control strategies with both 290 and $350-\mathrm{V}$ dc bus voltages, and these values are compared with the predicted simulation values in Table I. The measured torque values confirm that the average braking torque is low at all speeds for the test machine with the UCG strategy and that quantitative agreement between measured and simulated torque values is quite good. Unfortunately, it was not possible to obtain meaningful average torque measurements for the shorted-phase case due to torquemeter instru- mentation problems caused by the high ac pulsating torque amplitude.

\section{CONCLUSION}

This paper has developed a $d q$ synchronous reference frame model for an interior permanent magnet synchronous machine that is valid when one of the phases is open-circuited. The model order is reduced from two to one compared to the standard condition of continuous currents in all three phases. As a result, a single nonlinear differential equation is sufficient to analyze the dynamic machine behavior in this mode when the rotor speed is fixed.

Using this model, system response to a fault caused by a sudden opening of one phase has been investigated. Key observations from this investigation include the following.

- If the action taken by the control is to remove the gate pulses from the inverter switches, the resulting system response is totally benign at low speeds. Sustained fault currents and torque will be induced only when the speed increases to the point that the line-to-line machine back-emf exceeds the dc link voltage. Pulsating braking torque is developed at these elevated speeds, and the average torque value will depend on the machine parameters. These trends make it desirable to design the IPM machine with the lowest possible magnet flux linkage $\Psi_{\text {mag }}$ and a high inductance saliency ratio $L_{q} / L_{d}$.

- If the action taken by the control is to short the remaining two unfaulted phases together, high-amplitude stator currents and pulsating torques will be induced at twice the excitation frequency due to the unbalanced excitation. Although the peak values are high for all speeds above a few percent of base speed, the average value of the fault braking torque will be low. The current and pulsating torque amplitudes will vary little over a wide speed range except at low speeds where the stator resistance exerts more influence to reduce the currents.

In conclusion, the open-circuit fault represents a relatively benign operating condition, particularly if the machine's back-emf is low (i.e., low $\Psi_{\text {mag }}$ ) and the post-fault control strategy is to immediately remove the switch gate pulses. Although a comprehensive investigation of the impact of machine parameters on post-fault behavior has not been conducted, all available evidence suggests that the UCG control strategy results in less severe post-fault IPM machine performance than the phase-shorting strategy. This makes intuitive sense since the UCG strategy effectively introduces an offsetting voltage in series with the back-emf that reduces the resulting fault current and pulsating torque amplitudes.

As a final point, it is worth noting once more that post-fault IPM machine performance is sensitive to the choice of machine parameters including the axis inductances and the magnet flux linkage. This observation highlights the importance of coordinating the design of the IPM machine and the drive control strategy to optimize performance under both normal and faulted operating conditions. 


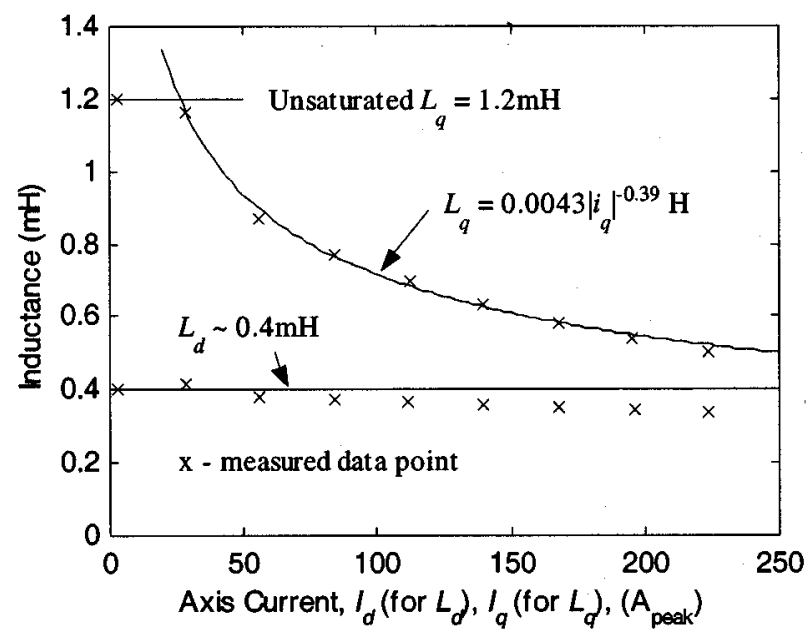

Fig. 15. Measured $d q$ inductances for the test machine.

\section{APPENDIX}

\section{Interior PeRmanent Magnet Machine PARAMETERS}

The three-phase, six-pole experimental IPM machine is rated at $70 \mathrm{~kW}, 4800 \mathrm{rpm}, 270 \mathrm{~V} \mathrm{rms}$, with the following parameters:

$$
\begin{aligned}
r_{s} & \approx 0.014 \Omega \quad \Psi_{\operatorname{mag}} \approx 0.10 \mathrm{~Wb} \quad L_{d} \approx 0.4 \mathrm{mH} \\
L_{q \max } & \approx 1.2 \mathrm{mH} \quad C_{1} \approx 0.0043 \mathrm{H} / \mathrm{Amp} \quad C_{2} \approx-0.39
\end{aligned}
$$

where $q$ axis inductance is approximated by a power series as

$$
L_{q}=L_{q \max } \text { or } L_{q}=C_{1}\left|i_{q}^{e}\right|^{C_{2}}
$$

whichever is smaller, so that

$$
\frac{\partial L_{q}}{\partial i_{q}^{e}}= \begin{cases}C_{1} C_{2}\left|i_{q}^{e}\right|^{\left(C_{2}-1\right)}, & L_{q} \leq L_{q \max } \\ 0, & \text { otherwise. }\end{cases}
$$

This power series model is capable of closely matching the measured $L_{q}$ values as shown in Fig. 15.

\section{ACKNOWLEDGMENT}

The authors wish to thank J. Nagashima, General Motors Advanced Technology Vehicles, for valuable technical assistance, the Staff of Wisconsin Electric Machines and Power Electronics Consortium, University of Wisconsin, for their motivation, and Dr. T. A. Lipo, University of Wisconsin, for helpful technical discussions.

\section{REFERENCES}

[1] W. Soong, "Design and modeling of axially-laminated interior permanent magnet motor drives for field-weakening applications," Ph.D. dissertation, Electron. Elect. Eng., Univ. Glasgow, 1993.

[2] T. M. Jahns, G. B. Kliman, and T. W. Neumann, "Interior PM synchronous motors for adjustable speed drives," IEEE Trans. Ind. Applicat., vol. IA-22, pp. 738-747, July/Aug 1986.

[3] B. A. Welchko, T. M. Jahns, W. L. Soong, and J. M. Nagashima, "IPM synchronous machine drive response to symmetrical and asymmetrical short circuit faults," in Proc. 9th Eur. Power Electron. Applicat., 2001.

[4] R. J. Kerkman, "Machine analysis with unbalanced terminal constraints by $d-q$ harmonic balance," Proc. Inst. Elect. Eng. B, vol. 128, pp. 343-357, Nov. 1981.

[5] R. J. Kerkman, P. C. Krause, and T. A. Lipo, "Simulation of a synchronous machine with an open phase," Elect. Mach. Electromech., vol. 1, pp. 245-254, 1977
[6] N. Bianchi, S. Bolognani, and M. Zigliotto, "Analysis of PM synchronous motor drive failures during flux weakening operation," in Proc. Power Electron. Spec. Conf., vol. 2, June 1996, pp. 1542-1548.

[7] A. G. Jack, B. C. Mecrow, and J. A. Haylock, "A comparative study of permanent magnet and switched reluctance motors for high-performance fault-tolerant applications," IEEE Trans. Ind. Applicat., vol. 32 , pp. 889-895, July/Aug. 1996

[8] P. Krause, O. Wasynczuk, and S. D. Sudhoff, Analysis of Electric Machinery. New York: IEEE Press, 1995.

[9] T. M. Jahns and V. Caliskan, "Uncontrolled generator operation of interior PM synchronous machines following high speed inverter shutdown," IEEE Trans. Ind. Applicat., vol. 35, pp. 1347-1357, Nov./Dec. 1999.

[10] D. W. Novotny and T. A. Lipo, Vector Control and Dynamics of AC Drives. New York: Oxford Univ. Press, 1996.

[11] E. C. Lovelace, T. M. Jahns, and J. H. Lang, "A saturating lumped parameter model for an interior PM synchronous machine," IEEE Trans. Ind. Applicat., vol. 38, pp. 645-650, May/June 2002.

[12] E. C. Lovelace, "Optimization of a Magnetically Saturable Interior Permanent-Magnet Synchronous Machine Drive," Ph.D. dissertation, Elect. Eng. Comp. Sci., MIT, Cambridge, 2000.

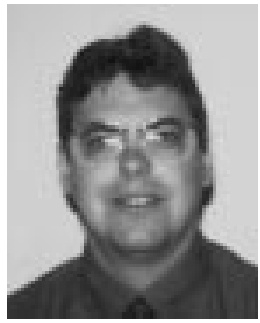

Brian A. Welchko (S'98) received the B.S. and M.S degrees from Ohio University, Athens, in 1994 and 1996, respectively, and is pursuing the Ph.D. degree at the University of Wisconsin (UW).

While at UW, he worked summers with the Otis Elevator Corporation and also at General Motors-Advanced Technology Vehicles. His research interests are in the control of induction and interior permanent magnet synchronous machines.

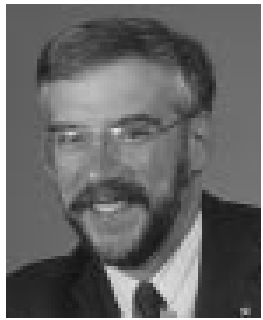

Thomas M. Jahns (S'73-M'79-SM'91-F'93) received the S.B. and S.M. degrees and the Ph.D. degree from the Massachusetts Institute of Technology (MIT), Cambridge, in 1974 and 1978, respectively.

He joined the faculty of the University of Wisconsin (UW), Madison, in 1998 as a Professor in the Department of Electrical and Computer Engineering, where he is also and Associate Director of the Wisconsin Electric Machines and Power Electronics Consortium (WEMPEC). Prior to coming to UW, he was with GE Corporate Research and Development, Schenectady, NY, for 15 years, where he pursued new power electronics and motor drive technology in a variety of research and management positions. His interests include permanent magnet synchronous machines for a variety of applications ranging from high-performance machine tools to low-cost appliance drives. From 1996 to 1998, he held a research sabbatical at MIT, where he directed research activities in advanced automotive electrical systems and accessories as co-director of an industry-sponsored automotive consortium

Dr. Jahns received the William E. Newell Award from the IEEE Power Electronics Society (PELS), in 1999. He has been recognized as a Distinguished Lecturer by the IEEE Industry Applications Society (IAS), from 1994 to 1995 and by IEEE-PELS, from 1998 to 1999. He has served as President of PELS (1995 to 1996) and as a member of the IAS Executive Board from 1992 to 2001

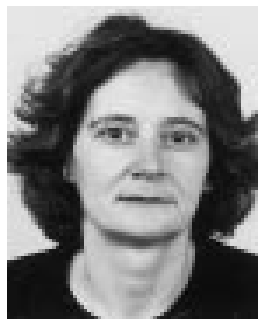

Silva Hiti (M'89) was born in Novi Sad, Yugoslavia. She received the B.S. degree from the University of Novi Sad, in 1987, the M.S. degree from the University of Maribor, Slovenia, in 1990, and the Ph.D. degree from the Virginia Polytechnic Institute and State University, Blacksburg, in 1996.

Since 1995, she has been with General Motors-Advanced Technology Vehicles, Torrance, CA, working on power electronics and motor drives applications for electric and hybrid-electric vehicles. She has published papers on modeling and control of ac motor drives and three-phase PWM converters with four U.S. patents in these areas. 